\title{
THE USE OF POLYETHYLENE AND RESINATED ASBESTOS FELT FOR SPLINTS
}

\author{
John T. Scales, London, England \\ From the Plastics Research Unit, Institute of Orthopaedics, \\ Royal National Orthopaedic Hospital, London
}

Since our last report (1948) two new materials, polyethylene and resinated asbestos laminate, have been introduced for the manufacture of splints. In this paper, preparation and working methods are described. The illustrations show stages in making a cervical collar and a hip spica. It will be clear that polyethylene* and resinated asbestos felt ${ }^{*}$ which have certain advantages over celluloid and moulded leather, should be regarded not as substitutes but as useful additions to a range of synthetic materials which permit the degrees of rigidity and flexibility required for various appliances.

\section{POLYETHYLENE}

Polyethylene was first introduced just before the recent war and is now used widely as an electrical insulant and for soles in footwear. Chemically it is similar to paraffin wax but because of its great molecular length, has quite different physical and mechanical properties. The name polyethylene is a general term covering a wide range of solid polymers of ethylene $\left(\mathrm{C}_{2} \mathrm{H}_{4}\right)$ prepared by subjecting gaseous ethylene to very high pressure under carefully controlled conditions. Chemically it is a straight-chain hydrocarbon of the form shown below:<smiles>CCCCC(C)(C)C(C)(C)C</smiles>

The individual molecules may contain as many as a thousand carbon atoms. It is a typical thermoplastic, melting at about 119 degrees centigrade to become a viscous liquid. In the softened state it can be extruded and moulded by compression or injection. At room temperatures it is tough and flexible, and remains so, well below 0 degrees centigrade. Though waxy in appearance, it is translucent in the range extending from the longest infra-red waves to about 2200 Angström units in the ultra-violet field. There are slight general absorption bands in the ultra-violet range but no sharp lines. This wide-range translucency is advantageous clinically because the splints need not be removed for treatment by ultra-violet light or sunlight. Prolonged ultra-violet irradiation may cause a slight yellow discolouration, but this is of no significance.

Polyethylene, with a specific gravity of $\mathbf{0 . 9 3}$, is one of the lightest thermoplastics yet produced (compare methyl-methacrylate, trade name "Perspex," specific gravity $1 \cdot 19$ ). It is almost insoluble in all organic liquids at room temperature. At higher temperatures it is soluble in a number of hydrocarbons and chlorinated hydrocarbons such as benzine, xylene, toluene, tetralin, petroleum ether, medicinal paraffin, lubricating oils, turpentine, trichlorethylene, carbon tetrachloride and chlorobenzine.

* Made by Imperial Chemical Industries, Ltd., under the trade name " Alkathene," in thicknesses from to in. to $\frac{1}{2}$ in.

$\dagger$ Made by Turner Brothers Asbestos Co., Ltd., Rochdale, under the trade name " Durestos," in three standard grades, RA1, RA2 and RA3, each in three thicknesses. 
After being worn for a few months, splints made from polyethylene tend to become a little yellow. This is thought to be due to slow oxidation-which does not, however, affect the strength or durability.

Manipulation of sheet polyethylene-Some points in the preparation of the positive and negative casts should be noted. 1) The plaster should extend two or three inches beyond the proposed margin of the splint, so that a good edge can be obtained by cutting back the material to the required size. 2) The positive should have a central core-space to permit economy in the use of plaster, ease of handling, suspension while in the oven and quicker drying. 3) The positive should be covered with a suitable "release" material so that the plastic does not bond itself to the plaster.

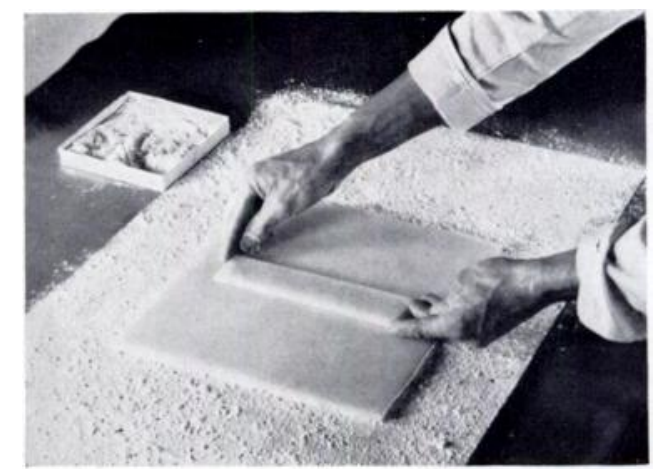

FIG. 1

Sheet polvethrlene with reinforcement strip on asbestos board, covered with lirench chalk and ready for heating.

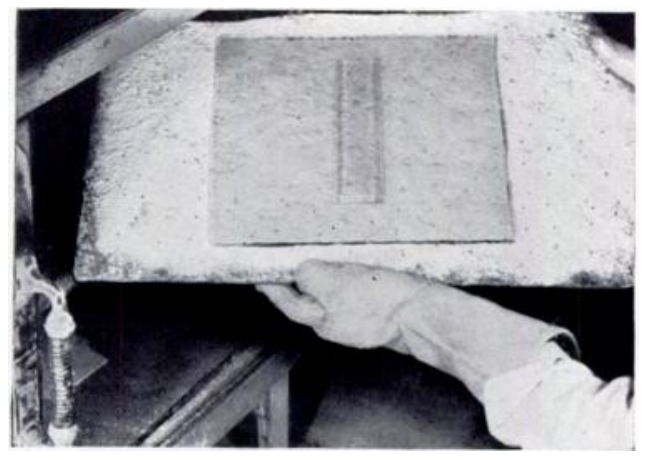

FIG. 2

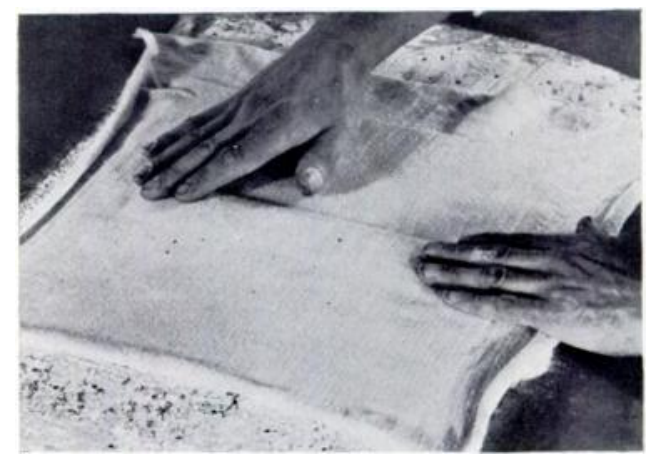

FIG. 3

After heating the sheet is transparent and viscous. It is ready for moulding over a plaster cast (Fig. 2). Stockinet is applied to the softened polyethylene as a "carrier" (Fig. 3).

Polyethylene is most suitable for splints in which some resiliency is allowed. Uncoloured sheets in thicknesses from $\frac{1}{16}$ inch to $\frac{3}{16}$ inch are used in orthopaedic work; greater thicknesses are not required. They should be free from anti-oxidant (polyisobutylene) which might cause dermatitis. The measurements of the positive plaster casts are taken and a margin of about one inch is allowed all round. A piece of polyethylene of the appropriate size is cut with an electric saw or, less easily, with a sharp leather-knife. If no reinforcement of the sheet is required it is placed on a perforated sheet of asbestos cement covered with French chalk to prevent adhesion of the material when it becomes soft (Fig. 1). The upper surface of the polyethylene is also covered with chalk. When reinforcement is required a strip $\frac{3}{16}$ inch thick is placed 
appropriately on the larger sheet before dusting with chalk. If the contact surfaces are absolutely clean, the two sheets fuse perfectly at melting heat.

With their covering of chalk, the sheets are heated for ten to fifteen minutes in a gas or electric oven controlled by a thermostat at 120 degrees centigrade till the opaque sheet becomes transparent (Fig. 2); over-heating will cause bubbles to form and prevent successful manipulation. Meanwhile the positive casts, held in a vice by means of a metal rod incorporated in the plaster, are also covered with French chalk to give a non-adhesive surface. When the polyethylene has been heated sufficiently a piece of stockinet, which will act as a " carrier," is gently pressed on so that the threads become embedded (Fig. 3). Woven glass-fibre can also be used as a carrier but, although it gives a better surface to the finished splint, the added expense is usually not justified. If a carrier is not used it is impossible to get a consistent thickness, as the hot polyethylene runs like treacle.

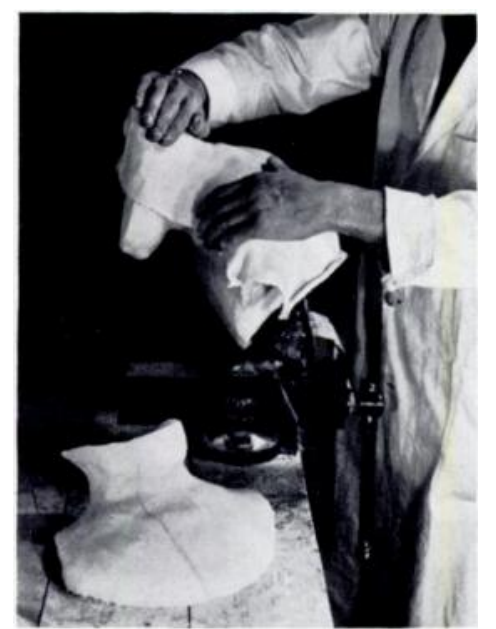

FIG. 4

The polyethylene and carrier are moulded over the plaster cast.

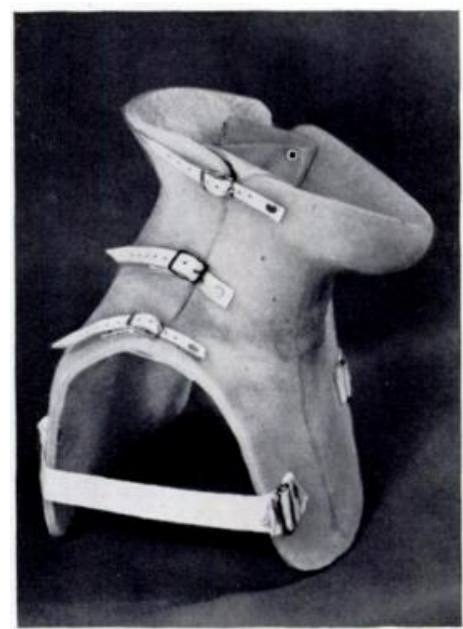

FIG. 5

A typical cervical collar made from polyethylene for an adult patient.

The material can then be applied to the cast (Fig. 4). One edge of the stockinet and polyethylene is tacked to the cast and the remainder is stretched gently into position. The operator, wearing asbestos gloves if desired, maintains the splint in close contact with the cast for ten to fifteen minutes while the material is cooling. The remaining edges of the splint are tacked into position and left to cool on the cast for half an hour before removal. (At this stage instantaneous cooling by immersion in water is permissible but may spoil the plaster cast.) The inner surface crinkles slightly and allows air to circulate beneath the appliance; a few $\frac{1}{8}$ inch air-holes may be drilled to assist ventilation. On the outer surface the impression of the stockinet is more pleasant to the touch than a wax-like plain surface. The rough splint is fitted to the patient, trimmed with a knife, or sawn and smoothed off at the edges. Buckles and straps, or zip-fasteners, are riveted in position; and tongues are fitted where the splint edges come together, to prevent nipping of the skin (Fig. 5). At body temperature the splint has slight resilience but is not readily deformed. It may be kept clean either with soap and water or with a detergent such as cetyl-trimethyl-ammonium bromide.

\section{RESINATED ASBESTOS FELT}

Phenol-formaldehyde is a resin produced by the inter-action of phenol and formaldehyde in suitable proportions in the presence of a condensation catalyst such as sodium hydroxide. The resin as first prepared has the property of being converted by heat into an insoluble 
solid, and is sprayed over asbestos fibres to form a "tacky" felt. Material in this raw condition is ready for the first stage in the manufacture of splints and appliances. In the process of preparation the asbestos fibres come to lie in the same direction; the material can therefore be stretched with the grain of the fibre but tears if pulled across the grain.

Phenol-formaldehyde resin has little intrinsic strength, and the strength of articles manufactured from it depends upon the use of a suitable "filler," in this case asbestos fibre. It is a thermo-setting plastic and is used in industry as a low-pressure (i.e., less than $100 \mathrm{lb} / \mathrm{sq}$. in.) laminating material. In the manufacture of splints and appliances, sufficient

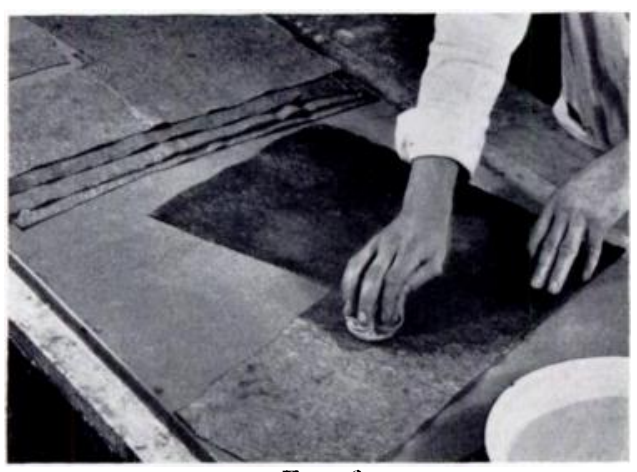

FIG. 6

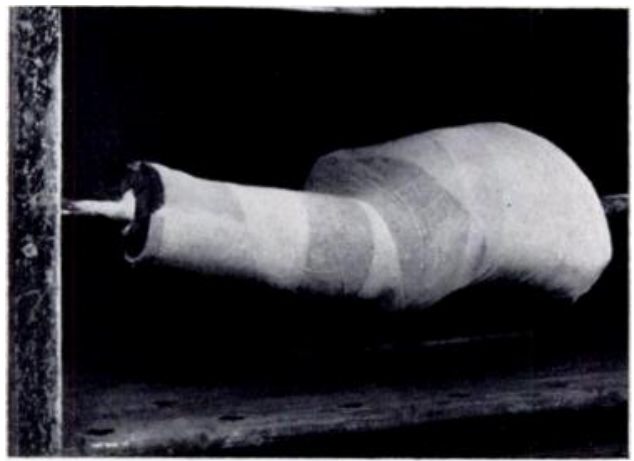

FIG. 8

Tailored sheets of resinated asbestos felt prepared for a hip spica. The sheets are moistened with water before moulding over the cast (Figs. 6 and 7). The edges are teased to make a good joint. The cast and splint are bound with woven cotton bandage and suspended in an oven for curing (Fig. 8). Two halves of the cured spica after trimming are shown in Figure 9.

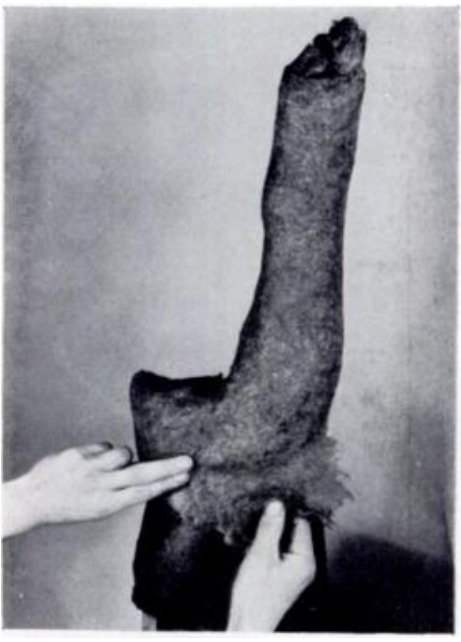

FIG. 7

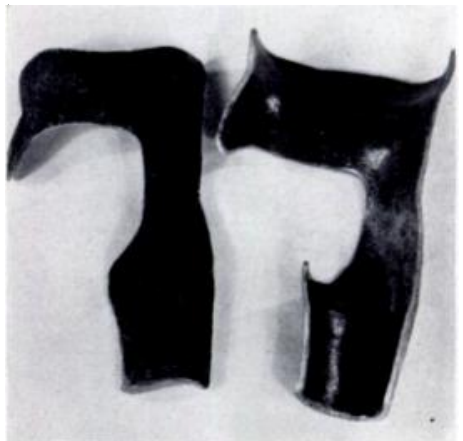

FIG. 9

pressure is exerted by the drying-out of woven linen or cotton bandage, or of water-wettable cellophane, applied to the outside of the cast. Tests on pieces of cured felt, which had been moulded under pressure obtained with such simple methods, showed the following average results:

Tensile strength: $5220 \mathrm{lb} / \mathrm{sq}$. in.

Shear strength: $3620 \mathrm{lb} / \mathrm{sq}$. in.

Cross-breaking tensile strength: $4000 \mathrm{lb} / \mathrm{sq}$. in.

Compression strength: $45,000 \mathrm{lb} / \mathrm{sq}$. in.

The specific gravity is $\mathbf{0} \cdot 81$.

The uncured material contains phenol and formalin and may cause skin irritation in 
susceptible persons concerned with handling or manipulation; this trouble can be avoided by using a barrier cream. The cured material of the finished splint is non-irritant.

Manipulation-The thin and medium thickness sheets are the most useful for moulding. Resin content and type of fibre vary with the specification: grade RA2 gives the best results in orthopaedic work. A spica is used here to illustrate the method of manipulation. The pieces are tailored in the manner shown in Figure 6. Two sheets are cut so that they can be applied right round the cast, and three to reinforce the back and the front. Off-cuts are used to strengthen the upper thigh, groin and buttock areas, where the greatest strain occurs. The felts are well damped with water to allow satisfactory moulding and bonding. The first large sheet is applied round the cast and the edges teased out to ensure a good joint on the lateral side. The smaller sheets are applied, one to the front and two to the back;

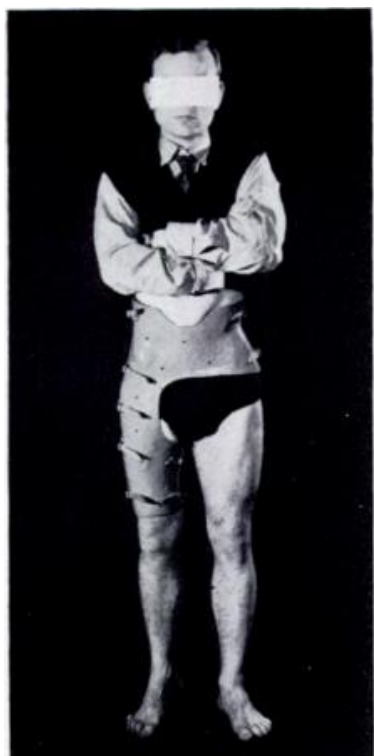

FIG. 10

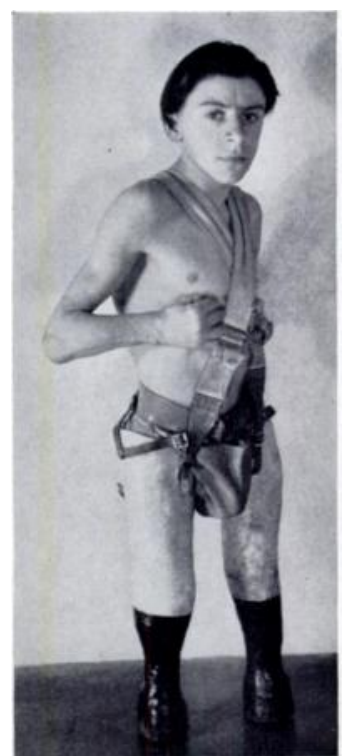

FIG. 11

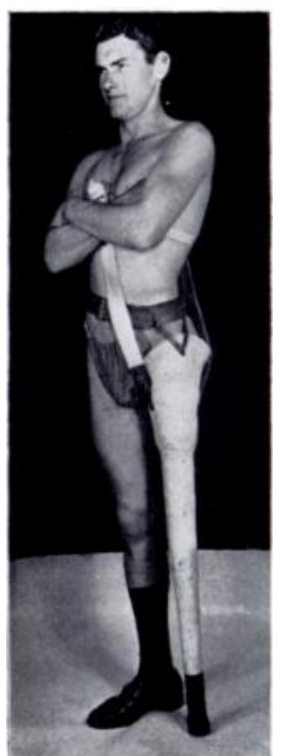

Fig. 12

The finished spica, weighing $2 \mathrm{lb} .4 \mathrm{oz}$. (Fig. 10). A dwarf with bilateral tuber-bearing laminated felt pylons, weighing $1 \mathrm{lb} .15 \mathrm{oz}$. and $2 \mathrm{lb} .4 \mathrm{oz}$. respectively (Fig. 11). A light tuber-bearing laminated felt pylon for an above-knee amputation, used by the patient alternately with his standard prosthesis which weighed $5 \mathrm{lb}$. $10 \mathrm{oz}$. without a shoe. A similar "Perspex" pylon weighed $5 \mathrm{lb} .8 \mathrm{oz}$. The appliance illustrated weighed $2 \mathrm{lb}$. and indeed it was so light that it was necessary to weight it with 20 ounces of lead at the lower end to give a good swing (Fig. 12).

and the whole is covered by the final large sheet. The grain of each succeeding layer should be laid at right angles to that of the preceding layer. (The direction of the grain is found easily on pulling the edge of the sheet.) All edges are well teased and smoothed into the layer beneath (Fig. 7). A smooth rubber roller may be used to ensure that all layers are well bonded. If time permits, the cast is allowed to dry for a few hours before the application of the bandage or cellophane. If a cellulose acetate solution is painted over the partly dry bandages, the evaporation of the solvent leaves a skin which contracts and gives a cast of superior strength and quality (Fig. 8). The splint is "cured " by heating. It is placed in a gas oven with the thermostat set at 75 degrees centigrade and allowed to cure for eight hours. At higher temperatures delamination is caused by the formation of steam. When cured, the spica is cut from the cast with a circular saw and, after fitting to the patient, finally trimmed. If ventilation holes are required they are drilled at this stage, before finishing. The inner surface is coated with a water emulsion of polyvinyl acetate, which on heating 
for a few minutes in an oven forms a protective skin. The outer surface is coated with aluminium paint and finished with flesh-coloured cellulose lacquer. Straps and buckles or zip-fasteners are applied on one side and lacings on the other (Fig. 10). Splints may be cleaned with soap and water.

Excluding curing, production time is approximately one quarter of that required for cellulose acetate or moulded leather splints, which have to be reinforced with steel; the cost is about one half. The further advantages of the material are that it is durable and light, does not distort with use, is washable, unaffected by sweat, urine and faeces; and is non-inflammable. It is most suitable for rigid splints such as pylons, spinal jackets, spicas and long-leg gutters.

Footnote 1-In the preparation of splints from sheet polyethylene, instead of the usual white finish it is possible to make a flesh-coloured splint by using pink "Crinothene," one-thousandth of an inch (the trade name of the thin type of polyethylene produced by Imperial Chemical Industries) which is placed on top of the polythene with or without reinforcing strips before the application of chalk. The two sheets are heated together and, when they become clear, fusion will occur.

Footnote 2-A recent improvement in the "Durestos" technique has been released for publication by the Ministry of Supply and described by L. N. Phillips of the Royal Aeronautical Establishment at Farnborough (British Plastics, October 1949, 535). It was thought that if: 1) the adhesion between the felt could be improved; 2) some means of internal constraint could be used to reduce spring-back of the felts during curing; 3 ) the phenolic resin could be induced to catalize at lower temperatures, a much stronger laminate would be secured. These objects have been achieved by using a resorcinol formaldehyde glue modified with furfuryl alcohol. "Aerolite 185," a commercial resorcinol formaldehyde glue is activated for use by the addition of one-fifth by weight of paraformaldehyde; furfuryl alcohol, 1 to 2 per cent., is added after compounding, and this aids in the dispersion of the glue through the felt. This glue reacts with the phenol resin present in the felts and enables them to be cured at lower temperatures than normal. The glue is spread on the felt during the laminating process by brushing, and about twenty-five square feet of felt per pound of resin can be so treated. The strength figures of the cured laminate are considerably increased and for some appliances this has been found to be an advantage.

I wish to thank Mr H. J. Seddon and other members of the staff of the Royal National Orthopaedic Hospital for their help and constructive criticism. Much credit is due to my technical assistant, $\mathrm{Mr} \mathrm{T}$. Fisher, for his ingenuity in perfecting the technical methods. I also wish to thank Mr G. May of Dufay-Chromex Ltd. and $\mathrm{Mr}$ S. Holt of I.C.I. (Plastics Division) Ltd., for their advice and for the supply of materials during the early stages of this work; Mr M. Howe of Turner Brothers Asbestos Co. Ltd., Rochdale, who arranged for strength tests on " Durestos "; Dr W. Bodger of Revertex Ltd., for various polyvinyl acetate emulsions : British Cellophane Ltd., for supply of material; and Mr T .Whitly for the photographs.

\section{REFERENCES}

Herschell, W., and Scales, J. T. (1948): Plastic Splints and Appliances in Orthopaedic Surgery. Journal of Bone and Joint Surgery, 30-B, 298. 